\title{
Approach for Assessing Coastal Vulnerability to Oil Spills for Prevention and Readiness Using GIS and the Blowout and Spill Occurrence Model
}

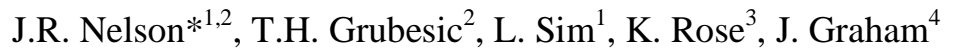

${ }^{1}$ Oak Ridge Institute for Science and Education, U.S. Department of Energy, National Energy

Technology Laboratory, 1450 Queen Avenue SW, Albany, OR 97321

${ }^{2}$ Center for Spatial Analytics and Geocomputation, College of Computing and Informatics, Drexel University, 3141 Chestnut Street, Philadelphia, PA 19104

${ }^{3}$ U.S. Department of Energy, National Energy Technology Laboratory, 1450 Queen Avenue SW, Albany, OR, 97321

${ }^{4}$ Environmental Science and Management, Humboldt State University, 1 Harpst St., Arcata, CA 95521

* Corresponding Author: jrn55@drexel.edu 


\title{
Approach for Assessing Coastal Vulnerability to Oil Spills for Prevention and Readiness Using GIS and the Blowout and Spill Occurrence Model
}

\begin{abstract}
:
Increasing interest in offshore hydrocarbon exploration has pushed the operational fronts associated with exploration efforts further offshore into deeper waters and more uncertain subsurface settings. This has become particularly common in the U.S. Gulf of Mexico. In this study we develop a spatial vulnerability approach and example assessment to support future spill prevention and improve future response readiness. This effort, which is part of a larger integrated assessment modeling spill prevention effort, incorporated economic and environmental data, and utilized a novel new oil spill simulation model from the U.S. Department of Energy's National Energy Technology Laboratory, the Blowout and Spill Occurrence Model (BLOSOM). Specifically, this study demonstrated a novel approach to evaluate potential impacts of hypothetical spill simulations at varying depths and locations in the northern Gulf of Mexico. The simulations are analyzed to assess spatial and temporal trends associated with the oil spill. The approach itself demonstrates how these data, tools and techniques can be used to evaluate potential spatial vulnerability of Gulf communities for various spill scenarios. Results of the hypothetical scenarios evaluated in this study suggest that under conditions like those simulated, a strong westward push by ocean currents and tides may increase the impacts of deep water spills along the Texas coastline, amplifying the vulnerability of communities on the local barrier islands. Ultimately, this approach can be used further to assess a range of conditions and scenarios to better understand potential risks and improve informed decision making for operators, responders, and a of stakeholders to support spill prevention as well as response readiness.
\end{abstract}

Keywords: Oil Spill, Simulation, Spatial Analysis, Response, Coastal Vulnerability, GIS

\section{Introduction}

Offshore fields in the Gulf of Mexico (GOM) are an integral part of the energy resources and national economy for the United States. Between 2008 and 2013, the GOM was responsible for upwards of $60 \%$ of the total crude oil produced in the United Sates (EIA, 2014). Because of the exceptional importance of oil to the US economy, it is no surprise that oil exploration in the GOM has been increasing. Advancing technologies, relatively steady increases in the price of oil, and key discoveries in deepwater and deep-subsurface settings make it economically feasible to push oil exploration further from shore and into more uncertain and challenging environments. The deep water (DW) and ultra-deep waters (UDW) now serve as the next frontier in oil exploration in the GOM and other offshore settings worldwide. However, the risks (e.g. environmental, operational, etc.) associated with DW and UDW settings are complex and generally less well understood and articulated (Jernelöv, 2010) than those associated with more well established onshore and shallow water operations.

An extreme example of what can occur when UDW technical and natural challenges coincide during offshore operations is illustrated by the events of 2010 (Board, 2011; Graham et al., 2011). The British Petroleum (BP) Deepwater Horizon semi-submersible oil platform experienced a catastrophic failure at the well head in the GOM. This resulted in the deaths of eleven workers and the closure of nearly 88,500 square miles of federal waters to fishing. The spill was extensive, lasted three months and had a profound impact on the economy and ecology surrounding the GOM (Graham et al., 2011). Not only did this uncontrolled release event illustrate key gaps in understanding how to prevent and respond to this type of spill, it brought to light the risks associated with oil exploration in the DW and UDW settings, particularly for the GOM (United States of America v. BP Exploration \& Production; Board, 2011; Graham et al., 2011; McNutt et al., 2011; Smith Jr et al., 2010). Although the economic feasibility 
of DW and UDW oil exploration remains unabated, social, environmental, and management issues associated with extraction efforts are now part of the international dialog. In particular, developing a deeper understanding of coastal vulnerability in the wake of an oil spill is critical for crafting efficient mitigation efforts and minimizing the impacts of oil spills for vulnerable communities. However, of equal importance is using the growing body of knowledge, data and tools to help understand vulnerabilities associated with current DW and UDW operations to identify trends, relationships, knowledge or technology gaps that support spill prevention and avoid rare but ultimately high impact effects of events as well as more common, lower impact events to ensure responsible development of offshore energy resources (Rose, 2014).

The purpose of this paper is to provide a stronger methodological and contextual foundation for evaluating the spatial vulnerability of coastal communities to DW and UDW oil spills in the Gulf of Mexico. Further, the developed approaches support both spill response preparedness and spill prevention efforts. Specifically, a suite of hypothetical offshore spill scenarios for a single time period are developed and combined with relevant economic and environmental data along with the U.S. Department of Energy's National Energy Technology Laboratory full water column system spill model, the Blowout and Spill Occurrence Model (BLOSOM). In unison, these methods and data are used to evaluate spill trends and identify the spatial vulnerability of coastal communities located on the GOM. Multiple spill simulations are performed at varying water depths for locations in the northern GOM and the results are analyzed to assess the behavior of the oil spill and to evaluate potential community impacts resulting from the spill.

\section{Background}

There are many types of coastal hazards which generally fall under the categories of natural or anthropogenic. For example, a significant body of literature explores the impacts of flooding from sea level rise (Nicholls, 2004; Nicholls et al., 1999), hurricanes and tsunamis (Kleinosky et al., 2007), and degradation of coastal environments from pollution and erosion (Hughes et al., 2003). There is growing interest regarding pollution as a coastal hazard, especially with increased hydrocarbon exploration, extraction, and the associated major oil spills of the $20^{\text {th }}$ and $21^{\text {st }}$ centuries (DiGiacomo et al., 2004; Shahidul Islam and Tanaka, 2004). Almost one quarter of world's population (1.2 billion) resides within $100 \mathrm{~km}$ of the coast. It is expected that by 2030 nearly half of the global population will live in this zone (Small and Nicholls, 2003). Thus, the vulnerability of coastal areas is inextricably linked to the global population. In addition, this vulnerability is further intensified by community dependencies on coastal assets (e.g. economic, environmental, etc.) (O'Keefe et al., 1976). One way to help improve community resiliency and coastal preparedness is through vulnerability assessments that identify the potential locations and magnitudes of natural or technological threats.

The scale and scope of vulnerability assessments can vary, but a core tenet of any assessment effort is to balance scientific findings with input from stakeholders that have different values and objectives (Linkov et al., 2006). As detailed previously, coastal hazards are highly diverse and as a result, coastal vulnerability assessments are particularly complex, requiring the incorporation of human activity, socio-economic structures, local ecosystems, habitats and physical processes such as morphology and sedimentology to get a more well-rounded and insightful assessment (Ahmad and Simonovic, 2012; Carlon et al., 2008; Fattal et al., 2010; Olita et al., 2012). One strategy for unifying this complex matrix of assessment parameters is the use of geographic information systems (GIS). GIS is particularly effective for evaluating and visualizing the underlying interconnections of the vulnerability matrix from a spatial perspective (Matisziw and Grubesic, 2013). In fact, the recognition and relevance of the spatial dimensions of vulnerability has prompted increased research effort in this domain, giving rise to a number of spatial vulnerability assessments (SVA), especially following the oil spills of the Exxon Valdez, Hebei 
Spirit, Prestige, and the most recent BP Deepwater Horizon spill (Cheong, 2012; French-McCay et al., 2009; Garza-Gil et al., 2006; Jensen et al., 1990).

Representative work on coastal hazards and vulnerability includes a SVA of Georgetown County, South Carolina (Cutter et al., 2000). Using a combination of GIS and basic spatial analysis, Cutter et al. (2000) integrated a suite of economic, demographic, social and environmental variables for capturing both the biophysical and population vulnerability of the region. Results suggest that population vulnerability does not necessarily correspond to the biophysical vulnerability of a region. In other work, a similar suite of key data and indicators describing the environment and economy have been used to support the development of risk indices, general risk assessment and decision support systems (DSS) for oil spill response (Fattal et al., 2010; Kankara and Subramanian, 2007; Wirtz and Liu, 2006). The data used in oil spill risk assessment are often divided into three categories including human, environmental, and infrastructural components for analysis (Tena-Chollet et al., 2013). This is also a strategy employed for the evaluation of other environmental hazards such as floods, hurricanes, and landslides (Ahmad and Simonovic, 2012; van Westen et al., 2008).

An important twist to traditional SVA efforts in this domain is the incorporation of an oil spill and transport model. There are a variety of oil spill models to choose from. For example, OilMap and OilMapDeep were created by ASA Science and include a very comprehensive suite of modeling and analysis tools such as $2 \mathrm{~d}$ and $3 \mathrm{~d}$ capabilities, weathering, surface and subsurface transport, and probability prediction of key areas being impacted by oil (Spaulding et al., 1992). However, the comprehensive and proprietary nature of these models can make them difficult to acquire. Alternatives include GNOME from the National Oceanic and Atmospheric Administration (NOAA). GNOME is freely available, but the current version is empirically limited because it is only 2-dimentional, limiting simulations to surface spills only (Zelenke et al., 2012). Another alternative is the Oil Spill Contingency and Response (OSCAR) model created by SINTEF (formally IKU Petroleum Research), which accounts for weathering and the related physical, biological, and chemical processes that effect oil (Aamo et al., 1996). However, like OilMap and OilMapDeep, OSCAR is proprietary. Finally, there is the Oil Spill Risk Analysis (OSRA) package created by the United States Geological Survey (USGS) (Smith et al., 1982), which combines both a risk assessment model and an oil spill fate and transport model for evaluating potential outcomes. However, this package is also tailored for surface spills and does not take into account subsurface plumes and their transport. Additionally, the OSRA package can only handle 31 potential "targets" that may be affected by a spill. In sum, these types of oil spill simulation techniques and packages are used widely, from delineating risk zones in Thailand (Singkran, 2013), to India (Kankara and Subramanian, 2007) and off the coast of Namibia (Reed et al., 1999), and each has constraints to its use or suitability.

For the empirical work in this paper, we used the National Energy Technology Laboratory's (NETL) Blowout and Spill Occurrence Model (BLOSOM), an oil spill simulation model that offers a flexible platform for simulating various types of oil spill events. In particular, there are several advantages offered by BLOSOM for evaluating the spatial vulnerability of communities and habitats proximal to DW or UDW spills. First, BLOSOM is being developed as an open source modeling suite. It is more comprehensive in its modeling abilities, encompassing the fate and transport of hydrocarbon from the seafloor, within the water column, and to the surface and shore. Because it will be released as an open source package, the research community will have the ability to customize BLOSOM for specific and emerging applications, create extensions and modify the code as needed. Second, BLOSOM has been designed specifically for modeling oil spills emanating from the deep ocean but can also be utilized for surface spills from tankers or shallow spills from pipelines or wells. As a result, BLOSOM is able to capture the dynamics associated with DW and UDW spills from source to sink. Finally, the plume component portion of BLOSOM was validated and tested against the SINTEF plume experiments 
conducted in the North Sea (Rye and Brandvik, 1997) and its relative performance and computational efforts were demonstrated to be competitive (Sim, 2013).

\section{Study Area, Data, Spill Scenarios and Methods:}

The Gulf of Mexico (Figure 1) is an elliptical basin located in between Florida and Texas in the southern US. It has roughly $2,624 \mathrm{~km}$ of ocean shoreline covering a surface area of $1.6 \times 10^{6} \mathrm{~km}^{2}$ (LugoFernández et al., 2001; U.S. Environmental Protection Agency, 2012). The coastal zone of the GOM hosts a wide range of human activities and features a number of coastal habitats, which include salt and freshwater wetlands, mangroves, coral reefs, beaches, tidal flats, and salt marshes (National Ocean Service, 2011).

\section{〈Figure 1 HERE>}

Between 2008 and 2013, the GOM was responsible for approximately $60 \%$ of the total crude oil produced in the United Sates (EIA, 2014). 2014 statistics from the Bureau of Safety and Environmental Enforcement (BSEE, 2014) indicate that the GOM is home to 2,513 production platforms in water depths less than 500 feet and 73 in deepwater (> 500 feet). Although exact counts are unknown, it is estimated that there are nearly 27,000 abandoned oil and gas wells in the GOM (AP, 2010). One concern with these abandoned wells is that they could eventually repressurize, leading to future leaks and/or blowouts (AP, 2010) long after operations associated with them have concluded. Due to the range of offshore operations present in the GOM and data availability spanning the breadth of systems, the GOM provides an excellent location for assessing the modeling spatial vulnerability of communities approach for supporting spill prevention and response readiness in relation to DW and UDW hydrocarbon activities.

\subsection{Blowout and Spill Occurrence Model (BLOSOM):}

NETL's BLOSOM is an integrated simulation package written in the Java programming language (Sim 2013). It has been designed to simulate offshore oil spills resulting from DW and UDW well blowouts. BLOSOM has been constructed through the incorporation of sub models, including: the Jet/Plume model, Transport model, conversion model, weathering model, crude oil model, gas/hydrates model, and finally the incorporation of a hydrodynamic handler. The hydrodynamic handler can use multiple inputs to determine the tides, currents, and wind direction. Presently, BLOSOM is utilizing the Naval Coastal Ocean Model- American Seas (AmSeas NCOM) data provided by the Northern Gulf Institute. This data is collected as needed by the user and is provided in NetCDF format. BLOSOM is also flexible enough to allow for the adjustment of one or all of the input parameters. An overview of the model is in Rose et al., 2014, and is discussed more thoroughly in Sim, 2013.

\subsection{Vulnerability Assessment Grid:}

A vector grid spanning the entire GOM shoreline was created to capture and analyze underlying spatial data layers. The grid was extended out to sea by $5 \mathrm{~km}$ and extended inland $25 \mathrm{~km}$ for a total width of $30 \mathrm{~km}$. At a width of $30 \mathrm{~km}$, the barrier islands can be incorporated in the risk assessment as well as the economically important and environmentally sensitive bays that sit further inland. Grid cells of $2 \mathrm{~km} x$ $2 \mathrm{~km}$ were generated for analysis, providing a good balance between spatial resolution and computational requirements/effort. In fact, several different cell sizes were used to conduct a sensitivity analysis, but the results were relatively consistent. That said, the use of these vector grids is important because it provides one with the ability to represent multiple spatial resolutions (e.g. varied grid sizes), alternative spatial extents and the synthesis of many attributes. 


\subsection{Contextual Data}

Economic data were collected for all available years, 2005 to 2011, from the National Oceanic and Atmospheric Administration's (NOAA) Economics: National Ocean Watch (ENOW) viewer. The data was collected at the county level and reflected only the activities involved with the ocean sector. This included tourism and recreation, living resources, and marine transportation. For each year, the number of establishments, number of employees, gross domestic product (GDP), and wages were collected as economic vulnerability proxies. Values were averaged over 2005-2011 and then assigned to each county bordering the GOM (ENOW, 2011).

Environmental Sensitivity Index (ESI) values, created by NOAA (2014), were used for determining the sensitivity of exposed shorelines to oiling. Shorelines are assigned a value ranging between 1 and 10 (least to most sensitive) and can also include an associated letter, A - D (e.g. A1 or 10D), for discerning subcategories of shoreline sensitivity. For the purposes of this study, only the numbered values were used to categorize shorelines. In cases where the ESI database contained multiple typology values, the most frequent and/or dominant ESI value was assigned to each vector grid cell. Although some spatial resolution is lost in this process, the dominant values are representative of the general characteristics for each cell. For more details on the ESI, shoreline types and ranking scheme, see NOAA (2014).

One notable analytical challenge in dealing with these diverse datasets is the process of fusing and normalizing individual databases for comparative purposes. A Jenks natural breaks classification method was used to normalize data ranges, identify the optimal class breaks, and minimize the variance within each potential class (Jenks, 1977). For example, all data that consisted of a range of values (employees, GDP, establishments, wages, and ESI) were reclassified into five ordinal groups for analysis. Each data set was then aggregated into the cells of the generated vector grid, allowing it to reflect the associated economic and environmental attributes for each location. For the purposes of this analysis, cells were given an equivalent share of the ordinal group they were classified into. For example, if a county was given a reclassified score of 3 for the number of employees, all cells within that county would adopt a value of 3 for number of employees. Shoreline length was also calculated and assigned to each cell.

Finally, each of the point location data sets (sensitive areas, public beaches, city centers, hotel locations, and campgrounds) were joined to their respective grid cells and assigned values of 1 for occurrence and 0 for absence. By aggregating all of these data sets into a specific grid cell, the number, type, and intensity of activity that occurred in any given $2 \mathrm{~km} \times 2 \mathrm{~km}$ area along the GOM could be determined and used for the spatial vulnerability analysis.

\subsection{Spill scenarios}

For the scenarios used to demonstrate the spatial vulnerability approach six locations were chosen for simulation and were selected from DW and UDW settings in the U.S. GOM (Table 1). Locations included the Central GOM, Central-West, GOM and the Western GOM (Figure 1). These are all core regions for hydrocarbon operations in the GOM. In each region, both a DW and UDW well location was selected for analysis. Once selected, BLOSOM was used to conduct a hypothetical spill simulation for a two-month period using current and tide data from March 1, 2013. Thus, for this demonstration of the spatial vulnerability approach the temporal framework was the same. Blowout durations for these simulations lasted one week. From a computational perspective, BLOSOM can simulate a 60 day oil spill in 32 hours. However, as more oil parcels are introduced to the modeled area, (e.g. extending the initial blowout time) computational effort for the full spatial vulnerability approach increases. Thus, computing time constraints were considered in generating these demonstration scenarios. BLOSOM's primary 
outputs are text files of the location and characteristics related to the individual oil parcels every 24 hours. ${ }^{1}$

Table 1: The initial scenario settings with the locations and characteristics of each of the spill scenarios.

\begin{tabular}{|c|c|c|c|c|c|c|c|c|}
\hline Run & $\begin{array}{l}\text { Start } \\
\text { Date }\end{array}$ & $\begin{array}{l}\text { End } \\
\text { Date }\end{array}$ & Lat & Lon & $\begin{array}{l}\text { Depth } \\
\text { (ft.) }\end{array}$ & Lease Block & $\begin{array}{l}\text { Depth } \\
\text { Designation }\end{array}$ & $\begin{array}{l}\text { Blowout } \\
\text { Time }\end{array}$ \\
\hline 1 & 1-Mar & 30-Apr & 27.833 & -94.566 & 933 & East Breaks & DW & 1 week \\
\hline 2 & 1-Mar & 30-Apr & 27.782 & -92.768 & 945 & Garden Banks & DW & 1 week \\
\hline 3 & 1-Mar & 30-Apr & 27.966 & -90.718 & 855 & Ewing Bank & DW & 1 week \\
\hline 4 & 1-Mar & 30-Apr & 26.905 & -94.905 & 4852 & $\begin{array}{l}\text { Alaminos } \\
\text { Canyon }\end{array}$ & UDW & 1 week \\
\hline 5 & 1-Mar & 30-Apr & 28.722 & -88.376 & 5225 & $\begin{array}{l}\text { Mississippi } \\
\text { Canyon }\end{array}$ & UDW & 1 week \\
\hline 6 & 1-Mar & 30-Apr & 27.374 & -90.281 & 4170 & Green Canyon & UDW & 1 week \\
\hline
\end{tabular}

\subsection{Spill analysis}

For the demonstration spatial vulnerability simulated hypothetical blowouts, BLOSOM generated information pertaining to oil spill composition and location. Compositional measures included oil velocity $(\mathrm{x}, \mathrm{y}, \mathrm{z})$, mass of the crude, density of the crude, crude/gas fraction cut, temperature, and salinity. ${ }^{2}$ Additional information concerning the spatial extent of the spill was extracted using geocomputational approaches, namely, the generation of convex hulls around the distribution of spill points. When combined and synthesized in a GIS, the spatio-temporal dynamics of each blowout was tracked and the characteristics of the spill were recorded. This included tracking the spill across the GOM, monitoring the number of days until first landfall, the areal extent of each spill and the rate of oil evaporation. Once the simulation was completed, the final location of oil spill parcels were recorded, tabulated, and visualized in the GIS (Figures 2 and 3).

\section{$<$ Figure 2 HERE> \\ <Figure 3 HERE>}

\subsection{Spatial Vulnerability Calculations}

Once all spatial layers were associated with a grid cell, the next step in the spatial vulnerability approach relied on BLOSOM to determine the spatio-temporal location of the individual oil spill parcels that make up the location of the oil plume. The locations of the spill points were transformed into a raster surface where each cell in the raster had a value reflecting the count of spill parcels completely contained within a cell. The count was then extracted to the risk analysis grid to be used in the SVA calculation. Given the turbidity of the ocean and the rate of evaporation for oil, it is important to note that a blowout lasting one week is likely to be almost entirely evaporated after a two month period (Fingas, 1999) assuming no loss of oil to sedimentation or intra-water column plumes. But, regardless of the amount of oil entering the water column and ultimately reaching the sea surface, the spatial distribution of oil following a blowout is likely to remain the same because it is being driven by the currents, tides, and winds of the system. For this reason, the risk calculation did not take into account the amount of oil

\footnotetext{
${ }^{1}$ Oil parcels refer to the individual oil slicks that make up the oil plume. Parcels are modeled as points in space.

${ }^{2}$ For a complete table of the BLOSOM outputs see supplemental KML files.
} 
making landfall. Instead, this instance of the spatial vulnerability approach captures the frequency of oil spill parcels making landfall and their associated spatial distribution. However, for longer duration spills, oil volume could be used in this step. Specifically, the total number of oil spill parcels occurring within each grid cell was divided by the total number of oil parcels that made landfall to obtain an oil spill score:

$$
O_{s}=P_{o} / T_{o}
$$

where $P_{o}$ is the frequency of oil parcels in a grid cell and $T_{o}$ is the total oil spill parcels making landfall. In effect, this is a share-based measure. Thus, grid cells with higher $O_{s}$ values are indicative of locations that have accumulated a higher share of the oil parcels making landfall. Under the assumption that a higher portion of total oil in a particular location is likely to have a greater impact, $O_{s}$ values were integrated with the reclassified spatial data $\left(D_{n}\right)$ (e.g. establishments, employees, etc.) to compute an oil spill vulnerability score for each location, $\left(O_{v}\right)$. The vulnerability score at each location reflects the magnitude of potential oil landfall at each grid cell location and the estimated degree of impact as measured by the reclassified spatial data indicators:

$$
O_{v}=\sum_{i=1}^{n} D_{1}+D_{2}+D_{3}+\ldots+D_{n} \times O_{s}
$$

\section{Results:}

Simulation results for this suite of hypothetical spills used to illustrate the spatial vulnerability approach are summarized in Table 2. The spill scenarios that made landfall were the DW location in East Breaks (17 days) followed closely by the UDW example in Mississippi Canyon (20 days). The spill that took the longest time to make landfall was an UDW example in Green Canyon (41 days). Figure 4 illustrates the steadily growing spatial extent for each of the scenarios. Mississippi Canyon and Green Canyon had the largest geographic extents and both were UDW settings. The scenarios with the smaller extents, East Breaks and Ewing Bank, were DW settings located on the GOM shelf. Interestingly, for the first 11 days of simulation, each of the spill scenarios had roughly the same total area. However, by day 17, there is a clear separation between the sizes of the spills. Alaminos Canyon and East Breaks maintain a somewhat plateaued total extent around $1.0 \times 10^{5} \mathrm{~km}^{2}$. Ewing Bank had the largest extent of the DW locations but was still $1.0 \times 10^{5} \mathrm{~km}^{2}$ smaller than the smallest UDW spill extent.

Table 0: Characteristics describing the hypothetical spill scenarios at the end of the simulated1 week active spill,

\begin{tabular}{|c|c|c|c|c|c|c|c|}
\hline $\begin{array}{l}\text { Lease } \\
\text { Block }\end{array}$ & $\begin{array}{l}\text { Depth } \\
\text { Designation }\end{array}$ & $\begin{array}{l}\text { Distance } \\
\text { to Shore } \\
(\mathbf{k m})\end{array}$ & $\begin{array}{l}\text { Plume } \\
\text { direction }\end{array}$ & $\begin{array}{l}\text { Days } \\
\text { till first } \\
\text { oil } \\
\text { beached }\end{array}$ & $\begin{array}{l}\text { Days till } \\
\text { evap/beached }\end{array}$ & $\begin{array}{l}\text { Total } \\
\text { shoreline } \\
\text { oiled }(\mathbf{k m})\end{array}$ & $\begin{array}{l}\text { Max area } \\
\text { affected } \\
\left(\mathbf{k m}^{\wedge} \mathbf{2}\right)\end{array}$ \\
\hline $\begin{array}{l}\text { East } \\
\text { Breaks }\end{array}$ & DW & 144 & NWW & 17 & 27 & 499.018425 & $8.8 \times 10^{\wedge} 4$ \\
\hline $\begin{array}{l}\text { Garden } \\
\text { Bank }\end{array}$ & DW & 198 & NNW & 29 & 41 & 629.64 & $5.1 \times 10^{\wedge} 5$ \\
\hline $\begin{array}{l}\text { Ewing } \\
\text { Bank }\end{array}$ & DW & 118 & NNW & 35 & 45 & 846.757013 & $3.6 \times 10^{\wedge} 5$ \\
\hline $\begin{array}{l}\text { Alaminos } \\
\text { Canyon }\end{array}$ & UDW & 242 & NWW & 28 & 49 & 744.085845 & $1.1 \times 10^{\wedge} 5$ \\
\hline $\begin{array}{l}\text { Mississippi } \\
\text { Canyon }\end{array}$ & UDW & 77 & NWW & 20 & 35 & 834.9952 & $6.3 \times 10^{\wedge} 5$ \\
\hline $\begin{array}{l}\text { Green } \\
\text { Canyon }\end{array}$ & UDW & 186 & SNW & 41 & 41 & 986.0238 & $5.5 \times 10^{\wedge} 5$ \\
\hline
\end{tabular}
two month tracking time period. 
<Figure 4 HERE>

\subsection{Spatial Distribution of Oil:}

In addition to visualizing the geographic distribution of oil spill parcels on the final day of simulation (Figures 2 and 3) the frequency of oil spill parcels making landfall was summarized for each county (Figure 5). For these examples of hypothetical spills analyzed by the spatial vulnerability approach there are several patterns worth noting which can be evaluated further in future studies to see if they are unique to the parameters used for these specific scenarios or if they offer insights. First, there is a strong clustering of oil parcel landfall in Texas, particularly in areas between Nueces County and Jefferson County. For example, the Ewing Bank DW scenario had the highest concentration of oil in any one county as the currents and tides seemed to funnel the oil into Galveston Bay. The East Breaks blowout displayed fairly significant clustering in/around Aransas, Calhoun, and Matagorda counties, likely due to the blowout's close proximity to the Texas coast. Green Canyon affected the largest amount of shoreline at $986.02 \mathrm{~km}$ with oil making landfall in Texas, Louisiana and Alabama. Interestingly, although oil from the Ewing Bank blowout was highly concentrated in Galveston County, Texas, it affected the second largest amount of shoreline for all spills in this particular simulation.

\section{<Figure 5 HERE>}

\subsection{Oil Spill Vulnerability:}

Figures 6-8 illustrate how the vulnerability of these communities to potential oil spills can be visualized. In this context vulnerability is defined as the susceptibility to negative consequences emanating from an oil spill. There are two variables at play in these figures. First, the degree of oil spill vulnerability is color coded and categorized within five discrete groups. Yellow cells correspond to regions where oil spill vulnerability is low for that respective spill scenario, while red cells correspond to regions where oil spill vulnerability is very high for that respective scenario. For example, as detailed previously, the East Breaks blowout has the largest impact in/around Aransas, Calhoun, and Matagorda Counties. This is reflected by the large number of darker orange and red colored bars for cells proximal to these locations in Figure 6. Second, bar heights are used to compare the magnitudes (measure of degree) of oil spill vulnerability between different scenarios. Taller bars suggest higher levels of population, asset, and community vulnerability and that the frequency of oil spill landfall is high. Thus, tall red bars correspond to the most vulnerable locations in the GOM.

East Breaks, Alaminos Canyon, and Garden Bank generated the most spatially concentrated areas of vulnerability. The spatial distribution of vulnerability was similar for these three scenarios, with concentrations along the Texas coastline south of Galveston (Figure 6). These are the three most western blowout scenarios, so it makes sense that the high concentration of oil along the Texas coastline reflects blowout proximity to the coastal landmass. However, Ewing Bank, Green Canyon, and Mississippi Canyon had the widest geographic impacts and were located in the central and eastern parts of the GOM. Interestingly, the Green Canyon and Mississippi Canyon scenarios had generally low vulnerability scores in comparison to Ewing Bank which had the highest vulnerability score of any of the scenarios. It seems that the UDW nature of the Green Canyon and Mississippi Canyon scenarios may have played a role in the final amount of oil that surfaced and made landfall. Further, this result may be compounded by the overall distribution of oil. Since it is dispersed over such a large geographic area, no one region is overly saturated in these scenarios. 
For the hypothetical scenarios regarding spatial vulnerability, the most vulnerable areas were located closer to major cities and bays along the Texas coastline where community assets are the densest. For example, the highest impact scenario occurred during the Ewing Bank blowout - not only was there a significant frequency of oiling in/around Galveston Bay, the density of assets in this area helped yield extremely high vulnerability magnitudes (Figure 7). On average there are 3,500 employees working in ocean sector activities in Galveston Bay County contributing an average of $\$ 113$ million dollars to the GDP. Conversely, the portions of the Louisiana coast that were exposed to oil were generally low lying, swampy areas with fewer average employees $(500-1000)$ and lower average GDP ( \$69 million). Because the population and associated community assets are relatively sparse in these zones, spill impacts are less intense and vulnerabilities are lower (Figure 8). This result is reflected in the Ewing Bank, Mississippi Canyon, and Green Canyon scenarios.

\section{<Figure 6 HERE> <Figure 7 HERE> <Figure 8 HERE>}

\section{Discussion}

There are several facets of the results worth discussing in more detail. First, from an empirical perspective, the modeled spill scenarios enhanced our understanding about how oil spills at various depths and locations may behave in the Gulf of Mexico. For each of the scenarios evaluated, regardless of the original location and water depth of the spill, the plume had a very dominant westward movement, primarily due to the prevailing currents, tides and winds during the time period (March) modeled here. It is possible that the movement of the oil would be different during other times of year which is part of further analyses that are ongoing. However, for scenarios with similar physical oceanographic and atmospheric conditions to those demonstrated in these examples, there are important implications for the Texas Coast for spill prevention and response planning. Even the Mississippi Canyon spill, located off the coast of Louisiana and the most geographically remote blowout relative to Texas, made its way to the Texas coastline within two months. This powerfully underscores the high level of exposure that Texas exhibits for all the scenarios explored in this study during conditions akin to those simulated here. In part, this can be attributed to relatively strong economic, cultural and environmental dependence of Texas coastal communities on the GOM, and also to the large spatial extent of the Texas coast line as a whole. But it also demonstrates the effect of the physical oceanographic and atmospheric conditions on the ultimate fate and transport of released material as well. Evaluation of temporal and spatial effects on spill behavior have significance for a range of stakeholders including regulators, industry and others to assist with informed decision making and support spill prevention and also support response readiness.

A second interesting facet of the results from these particular spatial vulnerability scenarios is that distance to the nearest shore did not seem to play a role in determining where and when oil first made landfall. For example, oil from the East Breaks scenario, which starts $144 \mathrm{~km}$ from shore, makes landfall in 17 days, much earlier than both Mississippi Canyon (77 miles, 20 days) and Ewing Banks (118 miles, 35 days). Given the strong westward influence of the currents and tides, it appears that more western spill locations will make landfall first, at least during March.

A third important finding for these scenarios is UDW blowouts had a propensity to generate spills with larger spatial extents for the same volume of oil in comparison to that of the DW scenarios. This is not necessarily a bad outcome. Because the oil from the UDW scenarios was spread over a larger area, the resulting frequency of oil landfall was not overwhelming for any particular area in the GOM. Conversely, 
DW spills for these scenarios led to higher concentrations of vulnerability for many areas. The tipping point for significant differences in spatial extent between scenarios occurs after approximately 15 days of simulated spill time. From an emergency mitigation perspective, if this finding was to remain consistent during subsequent empirical work, it would suggest that response efforts (e.g. booming, dispersants, controlled burning, etc.) should be mobilized within the first 15 days to effectively minimize spill impacts and systematically reduce community vulnerability.

Fourth, it is important to note that the empirical findings from this work suggest that the integration of spatial data and oil spill simulations dramatically enhance the effectiveness of spatial vulnerability assessments for a wide range of hypothetical or actual scenarios. As detailed throughout, areas with the highest frequency of oil exposure were not necessarily the areas determined to be the most vulnerable. In short, there are significant spatial heterogeneities between oil exposure and vulnerability. As a result, empirical work that ignores the underlying spatial data representing at-risk areas, or the predicted areas of oil spill impacts, is likely biased and/or uncertain. It is also important to reiterate that areas receiving a high frequency of oil spill parcels, but lacking important economic and ecological assets, may not need as much protection as an area that is affected by fewer oil spill parcels, but has more sensitive economic and ecological resources. Because most local, regional and federal agencies are budget constrained and suffer from limited emergency response resources, the ability to prioritize mitigation efforts through the use of spatial vulnerability models to identify spill prevention efficiencies and strategies is a decided advantage.

Finally, it is important to acknowledge the limitations of the results used to demonstrate the approach. The numerical and spatial modeling was partially limited by the computational requirements of BLOSOM. Particle models are computationally intensive and this limits the length of time a blowout could be simulated. While efforts are ongoing to advance BLOSOM's computational speed and efficiency, including developing a version for supercomputing use, at present its configuration limits the duration of spills that can be used for the spatial vulnerability approach. In addition BLOSOM runs on the data provided by the Northern Gulf Institute's current and tide data. The resolution of the data set $(\sim 3 \mathrm{~km})$ must be considered when assessing risk for barrier islands along Texas. In most areas along the GOM coast the actual shoreline and current data match. However, the barrier islands along Texas are too small to be incorporated at the $3 \mathrm{~km}$ resolution of the current and tide data. Also, a fairly high degree of uncertainty is acknowledged for the many bays of Texas and how oil may interact with these zones. At this point BLOSOM cannot predict whether the barrier islands would completely stop the oil from getting into the bays, however, there are near-shore spill modeling efforts ongoing that could be used to complement outputs of BLOSOM and improve the accuracy of the near-shore fate and transport of spill scenarios for future spatial vulnerability analyses. In regards to sensitivity of BLOSOM to changes in location and depth, the generated results were expected. Each location modeled had a different set of environmental conditions and each of the locations resulted in varying degrees of coastal vulnerability. However, to understand a range of coastal vulnerabilities, additional simulations with varying temporal and spatial attributes will need to be completed in support of spill prevention and response preparedness.

\section{Conclusion}

The Deepwater Horizon blowout was unprecedented in the history of offshore hydrocarbon development. Never before had a spill of that magnitude been experienced in U.S. waters. The event itself, however, highlighted how offshore hydrocarbon operations have pushed the fronts associated with exploration efforts further offshore into deeper waters and more uncertain subsurface settings requiring better tools, data and approaches in order to prevent future deleterious events while bolstering response readiness. 
The purpose of this paper was to offer and demonstrate a new approach for better understanding both the spatial and temporal characteristics of DW and UDW oil spills and to determine where potential vulnerabilities may exist. By characterizing spill events across the GOM through the combination of numerical and spatial modeling, a deeper understanding of the in-situ system and its associated dynamics can be developed for a range of hypothetical and actual scenarios. These results can be used by a range of stakeholders to improve decision making, reduce knowledge and technology gaps for spill prevention, and improve overall preparedness. It also highlighted distinctive spatial heterogeneities in the vulnerability landscape, underscoring the importance of spatial data and analysis to the modeling framework. Specifically, this study demonstrated a novel approach to evaluate the vulnerabilities related to hypothetical spill simulations at varying depths and locations in the northern GOM. The simulations are analyzed to assess spatial and temporal trends associated with the oil spill. Results of the hypothetical scenarios evaluated in this study suggest that under conditions like those simulated, a strong westward push by ocean currents and tides may increase the impact of deep water spills along the Texas coastline, amplifying the vulnerability of communities on the local barrier islands. Ultimately, the spatial vulnerability approach can be used further to assess a range of conditions and scenarios to better understand potential risks and improve informed decision making for operators, responders, and stakeholders to support spill prevention as well as response readiness.

\section{Acknowledgements}

This work was completed as part of National Energy Technology Laboratory (NETL) research for the department of Energy's (DOE) Complementary Research Program under section 999 of the Energy Policy Act of 2005. The authors also wish to acknowledge the National Energy Technology Lab in Albany, Oregon for collaboration and support of this work including help with data collection, processing, and the use of BLOSOM.

\section{References}

United States of America v. BP Exploration \& Production. United States District Court for the Eastern District of Louisiana, p. 5.

Aamo, O.M., Reed, M., Downing, K., 1996. Calibration, verification, and sensitivity analysis of the SINTEF oil spill contingency and response (OSCAR) model system. Report.

Ahmad, S.S., Simonovic, S.P., 2012. Spatial and temporal analysis of urban flood risk assessment. Urban Water Journal 10, 26-49.

Board, M., 2011. Macondo Well Deepwater Horizon Blowout: Lessons for Improving Offshore Drilling Safety. The National Academies Press, Washington, DC.

BSEE, 2014. Offshore Statistics by Water Depth. Bureau of Safety and Environmental Enforcement

Carlon, C., Pizzol, L., Critto, A., Marcomini, A., 2008. A spatial risk assessment methodology to support the remediation of contaminated land. Environment International 34, 397-411. 
Cheong, S.-M., 2012. Fishing and tourism impacts in the aftermath of the Hebei-Spirit oil spill. Journal of Coastal Research 28, 1648+.

DiGiacomo, P.M., Washburn, L., Holt, B., Jones, B.H., 2004. Coastal pollution-hazards in southern California observed by SAR imagery: stormwater plumes, wastewater plumes, and natural hydrocarbon seeps. Marine Pollution Bulletin 49, 1013-1024.

EIA, 2014. Crude Oil Production, in: pet_crd_crpdn_adc_mbbl_m.xls (Ed.). U.S. Energy Information Association.

ENOW, N., 2011. Gulf of Mexico Ocean Sector Activity, in: Management, O.o.C. (Ed.). NOAA, ENOW.

Fattal, P., Maanan, M., Tillier, I., Rollo, N., Robin, M., Pottier, P., 2010. Coastal Vulnerability to Oil Spill Pollution: the Case of Noirmoutier Island (France). Journal of Coastal Research 26, 879-887.

Fingas, M.F., 1999. The Evaporation of Oil Spills: Development and Implementation of New Prediction Methodology. International Oil Spill Conference Proceedings 1999, 281-287.

French-McCay, D., Beegle-krause, C., Rowe, J., Rodriguez, W., Etkin, D.S., 2009. Oil Spill Risk Assessment - Relative Impact Indices by Oil Type and Location, 32nd AMOP Technical Seminar on Environmetal Contamination and Response, Ottawa, Canada, pp. 655-681.

Garza-Gil, M.D., Prada-Blanco, A., Vázquez-Rodríguez, M.X., 2006. Estimating the short-term economic damages from the Prestige oil spill in the Galician fisheries and tourism. Ecological Economics 58, 842849.

Graham, B., Reilly, W.K., Beinecke, F., Boesch, D.F., Garcia, T.D., Murray, C.A., Ulmer, F., 2011. Deep Water: The Gulf Oil Disaster and the Future of Offshore Drilling: Report to the President. National Commission on the BP Deepwater Horizon Spill and Offshore Drilling, Washington, D.C., p. 398.

Hughes, T.P., Baird, A.H., Bellwood, D.R., Card, M., Connolly, S.R., Folke, C., Grosberg, R., HoeghGuldberg, O., Jackson, J.B.C., Kleypas, J., Lough, J.M., Marshall, P., Nyström, M., Palumbi, S.R., Pandolfi, J.M., Rosen, B., Roughgarden, J., 2003. Climate Change, Human Impacts, and the Resilience of Coral Reefs. Science 301, 929-933.

Jenks, G.F., 1977. Optimal data classification for choropleth maps: Occasional Paper No. 2. University of Kansas, Department of Geography.

Jensen, J.R., Ramsey, E.W., Holmes, J.M., Michel, J.E., Savitsky, B., Davis, B.A., 1990. Environmental sensitivity index (ESI) mapping for oil spills using remote sensing and geographic information system technology. International Journal of Geographical Information Systems 4, 181-201.

Jernelöv, A., 2010. The Threats from Oil Spills: Now, Then, and in the Future. AMBIO 39, 353-366. 
Kankara, R.S., Subramanian, B.R., 2007. Oil Spill Sensitivity Analysis and Risk Assessment for Gulf of Kachchh, India, using Integrated Modeling. Journal of Coastal Research, 1251-1258.

Kleinosky, L.R., Yarnal, B., Fisher, A., 2007. Vulnerability of Hampton Roads, Virginia to storm-surge flooding and sea-level rise. Natural Hazards 40, 43-70.

Linkov, I., Satterstrom, F.K., Kiker, G., Batchelor, C., Bridges, T., Ferguson, E., 2006. From comparative risk assessment to multi-criteria decision analysis and adaptive management: Recent developments and applications. Environment International 32, 1072-1093.

Lugo-Fernández, A., Morin, M.V., Ebesmeyer, C.C., Marshall, C.F., 2001. Gulf of Mexico Historic (1955-1987) Surface Drifter Data Analysis. Journal of Coastal Research 17, 1-16.

Matisziw, T., Grubesic, T., 2013. Geographic perspectives on vulnerability analysis. GeoJournal 78, 205207.

McNutt, M., Camilli, R., Guthrie, G., Hsieh, P., Labson, V., Lehr, B., Maclay, D., Ratze, A., Sogge, M., 2011. Assessment of Flow Rate Estimates for the Deepwater Horizon / Macondo Well Oil Spill. Flow Rate Technical Group report to the National Incident Command. Interagency Solutions Group.

National Ocean Service, N., 2011. The Gulf of Mexico at a Glance, A Second Glance. US Department of Commerce, Washington, DC.

Nicholls, R.J., 2004. Coastal flooding and wetland loss in the 21st century: changes under the SRES climate and socio-economic scenarios. Global Environmental Change 14, 69-86.

Nicholls, R.J., Hoozemans, F.M.J., Marchand, M., 1999. Increasing flood risk and wetland losses due to global sea-level rise: regional and global analyses. Global Environmental Change 9, Supplement 1, S69S87.

O'Keefe, P., Westgate, K., Wisner, B., 1976. Taking the naturalness out of natural disasters. Nature 260, 566-567.

Olita, A., Cucco, A., Simeone, S., Ribotti, A., Fazioli, L., Sorgente, B., Sorgente, R., 2012. Oil spill hazard and risk assessment for the shorelines of a Mediterranean coastal archipelago. Ocean \& Coastal Management 57, 44-52.

Reed, M., Ekrol, N., Rye, H., Turner, L., 1999. Oil Spill Contingency and Response (OSCAR) Analysis in Support of Environmental Impact Assessment Offshore Namibia. Spill Science \& Technology Bulletin 5, 29-38.

Rose, K., Aminzadeh, F., Sim, L., Ghanem, R. G., Disenhof, C., Bauer, J., Mark-Moser, M., Thimmisetty, C., Jabbari, N., and Khodabakhshnejad, A., 2014. Risks and Impact Assessment for Deepwater and Ultra-Deepwater Gulf of Mexico Resources, Offshore Technology Conference, p. 17. 
Rye, H., Brandvik, P.J., 1997. Verification of Subsurface Oil Spill Models, International Oil Spill Conference, Fort Lauderdale, Florida, pp. 551-557.

Shahidul Islam, M., Tanaka, M., 2004. Impacts of pollution on coastal and marine ecosystems including coastal and marine fisheries and approach for management: a review and synthesis. Marine Pollution Bulletin 48, 624-649.

Sim, L.H., 2013. Blowout and Spill Occurrence Model, College of Earth, Ocean, and Atmospheric Sciences. Oregon State University, Corvallis, OR, p. 103.

Singkran, N., 2013. Classifying risk zones by the impacts of oil spills in the coastal waters of Thailand. Marine Pollution Bulletin 70, 34-43.

Small, C., Nicholls, R.J., 2003. A Global Analysis of Human Settlement in Coastal Zones. Journal of Coastal Research 19, 584-599.

Smith Jr, L.C., Smith, L.M., Ashcroft, P.A., 2010. Analysis of environmental and economic damages from British Petroleum's Deepwater Horizon oil spill. Alb. L. Rev. 74, 563.

Smith, R.A., Slack, J.R., Wyant, T., Lanfear, K.J., 1982. Oilspill risk analysis model of the US Geological Survey. Geological Survey, Reston, VA (USA).

Spaulding, M.L., Howlett, E., Anderson, E., Jayko, K., 1992. OILMAP: A global approach to spill modeling.

Tena-Chollet, F., Tixier, J., Dusserre, G., Mangin, J.F., 2013. Development of a spatial risk assessment tool for the transportation of hydrocarbons: Methodology and implementation in a geographical information system. Environmental Modelling \& Software 46, 61-74.

U.S. Environmental Protection Agency, 2012. General Facts about the Gulf of Mexico. U.S. Environmental Protection Agency.

van Westen, C.J., Castellanos, E., Kuriakose, S.L., 2008. Spatial data for landslide susceptibility, hazard, and vulnerability assessment: An overview. Engineering Geology 102, 112-131.

Wirtz, K.W., Liu, X., 2006. Integrating economy, ecology and uncertainty in an oil-spill DSS: The Prestige accident in Spain, 2002. Estuarine, Coastal and Shelf Science 70, 525-532.

Zelenke, B., O’Connor, C., Barker, C., Beegle-Krause, C.J., Eclipse, L., 2012. General NOAA Operational Modeling Environment (GNOME) Technical Documentation. US Dept. of Commerce. NOAA Technical Memorandum NOS OR\&R 40, 105.

Figure 1 - Gulf of Mexico study area showing the modeled blowout locations (red dots). In addition, the contours represent the boundary for DW (green) and UDW (red) well depths for the Gulf of Mexico. 
606 Figure 2 - Extent of the hypothetical DW spills following the 1 week blowout and two months of tracking 607 the simulated scenarios.

608 Figure 3 - Extent of the hypothetical UDW spills following the 1 week blowout and two months of 609 tracking the simulated scenarios.

610 Figure 4 - Oil extent as a function of hypothetical simulated day. The two largest spills following the 611 simulated two month period are UDW well locations.

612 Figure 5 - Histogram of oil spill parcels (points) by county. Each bar represents the total number of oil 613 parcels making landfall within the specific counties surrounding the Gulf of Mexico. High clustering is 614 occurring in the state of Texas.

615 Figure 6 - East Breaks scenario vulnerability scores.

616 Figure 7 - Ewing Bank scenario vulnerability scores.

617 Figure 8 - Mississippi Canyon scenario vulnerability scores.

618 


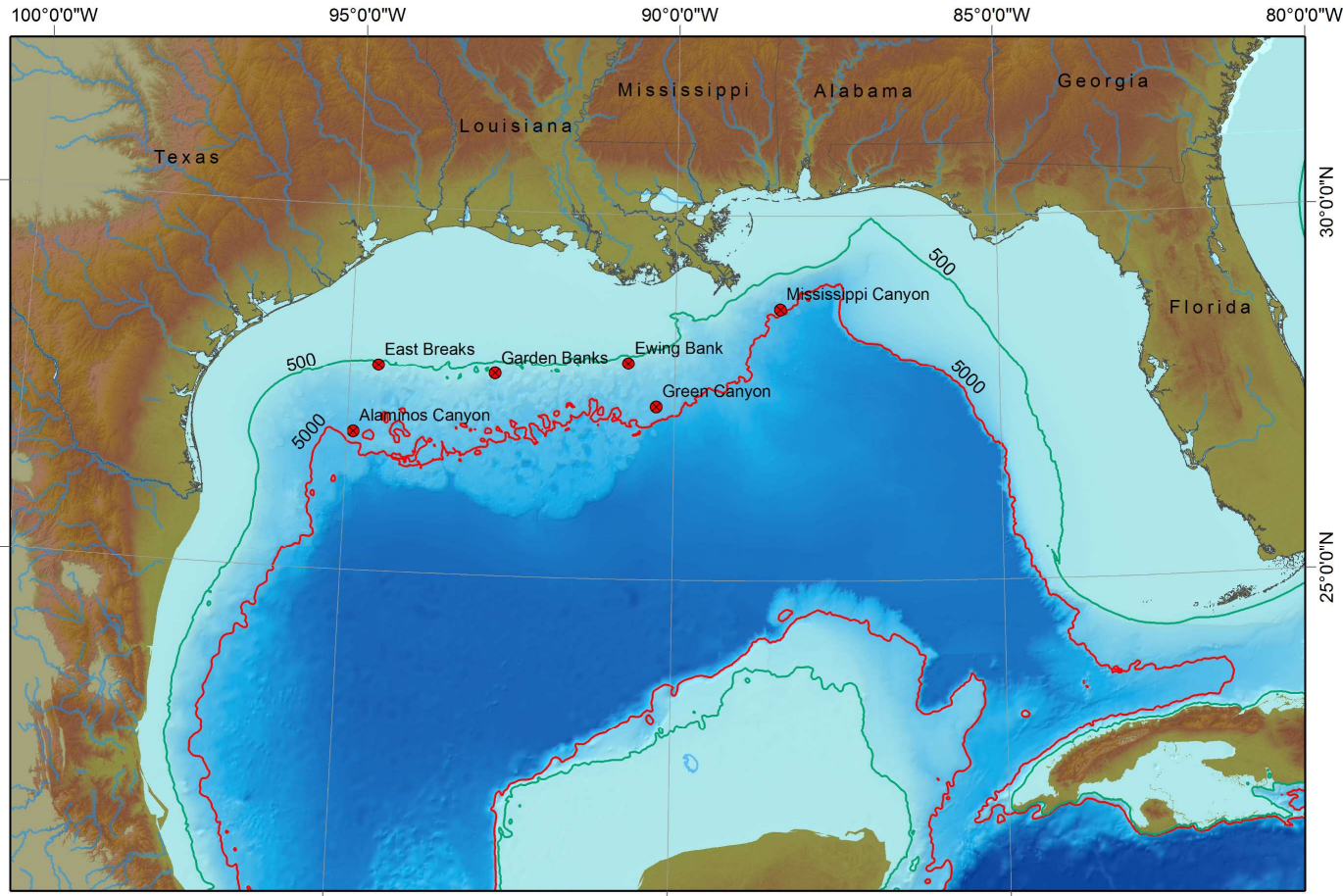




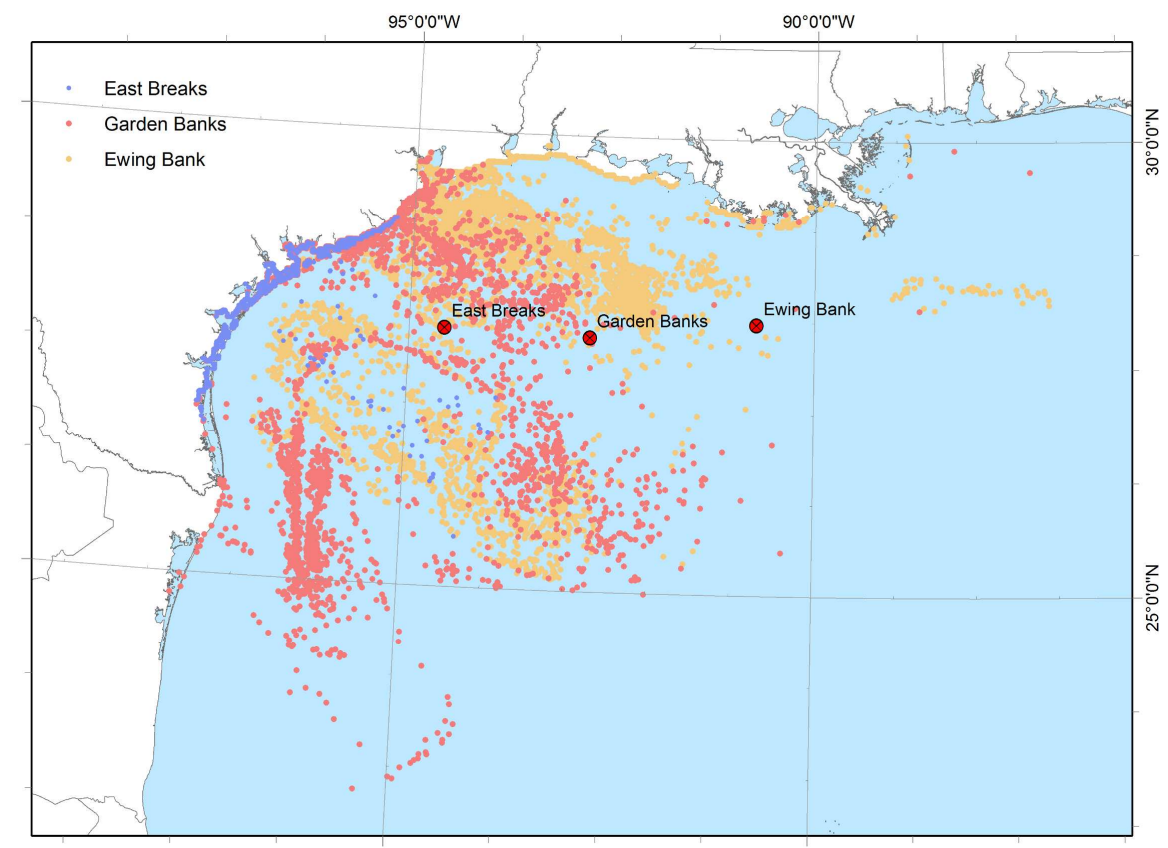




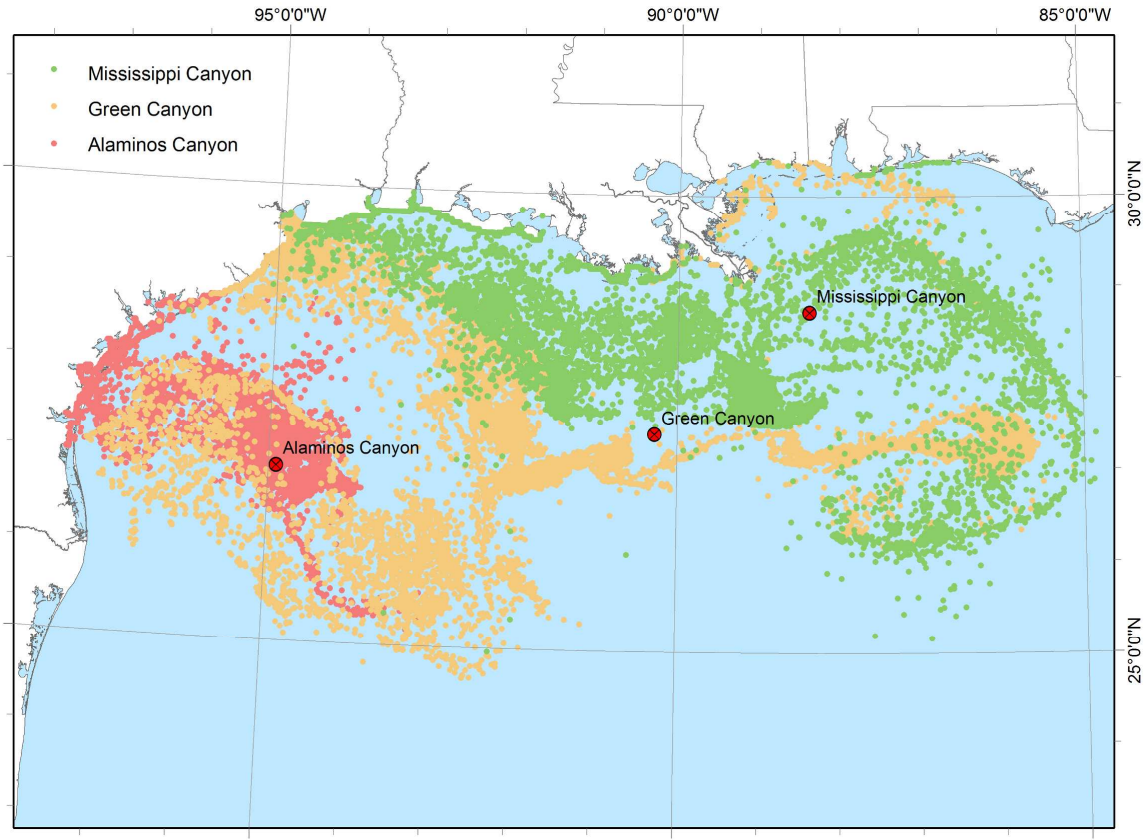




\section{Oil Extent vs. Day}

$\multimap$ East Break $\longrightarrow$ Alaminos Canyon $\multimap$ Ewing Bank

$\longrightarrow$ Garden Bank $\longrightarrow$ Mississippi Canyon $\longrightarrow$ Green Canyon

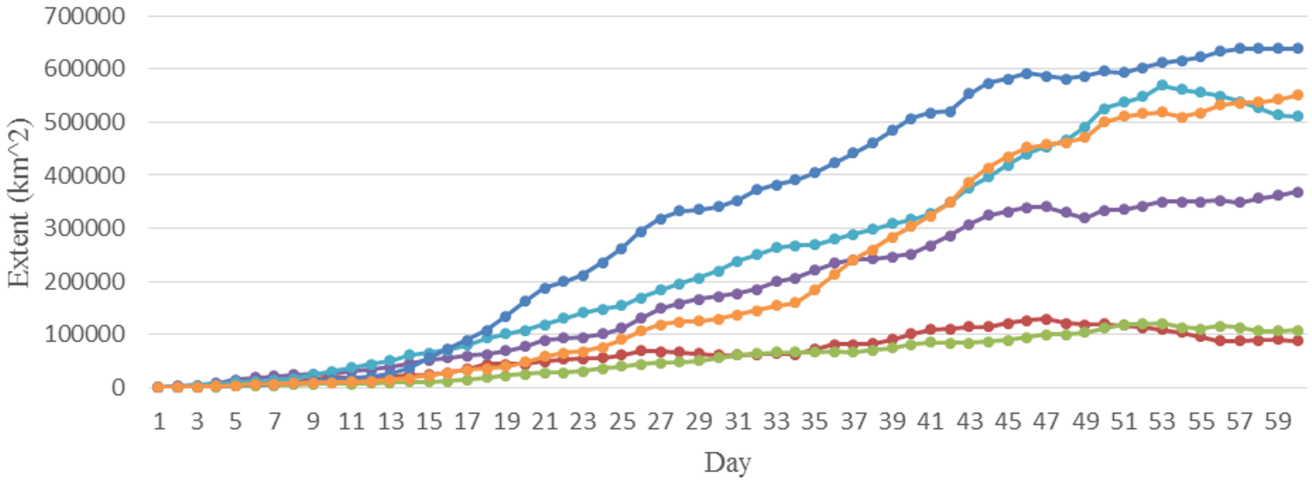




\section{Frequency of Oil Spill Parcels by County}

- Alaminos Canyon

East Breaks

Ewing Bank

- Garden Banks

Mississippi Canyon

- Green Canyon

6000

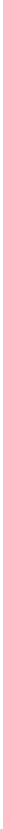




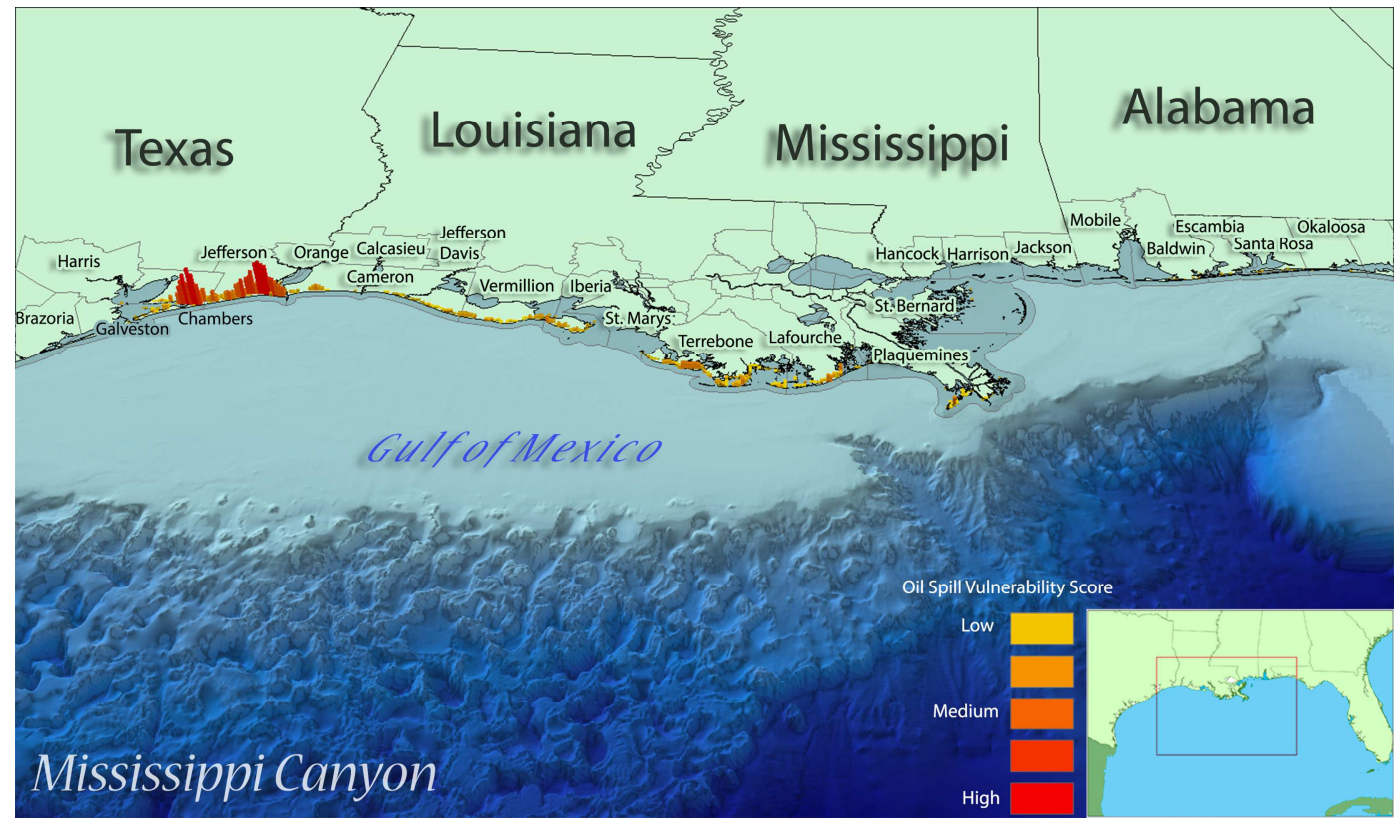




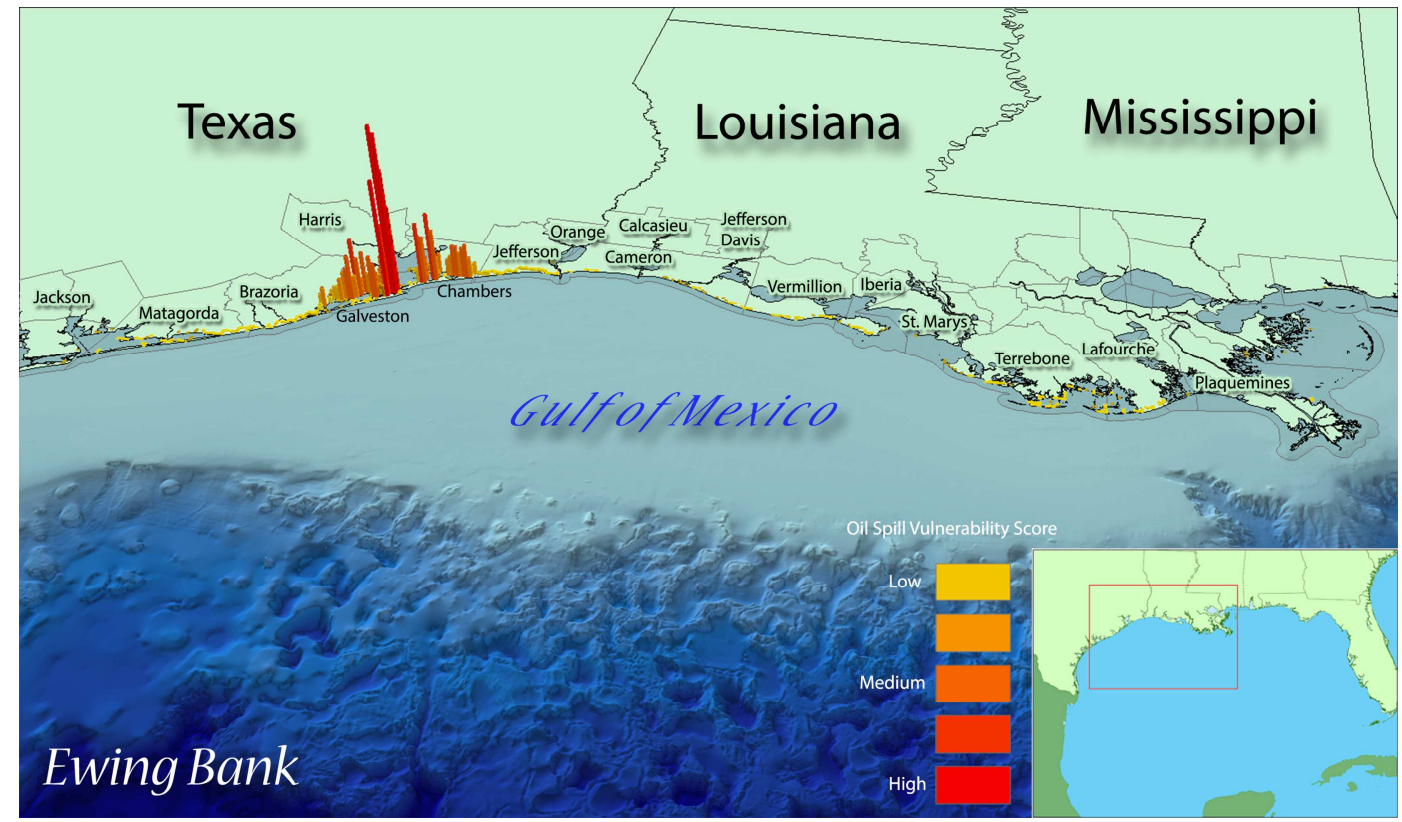




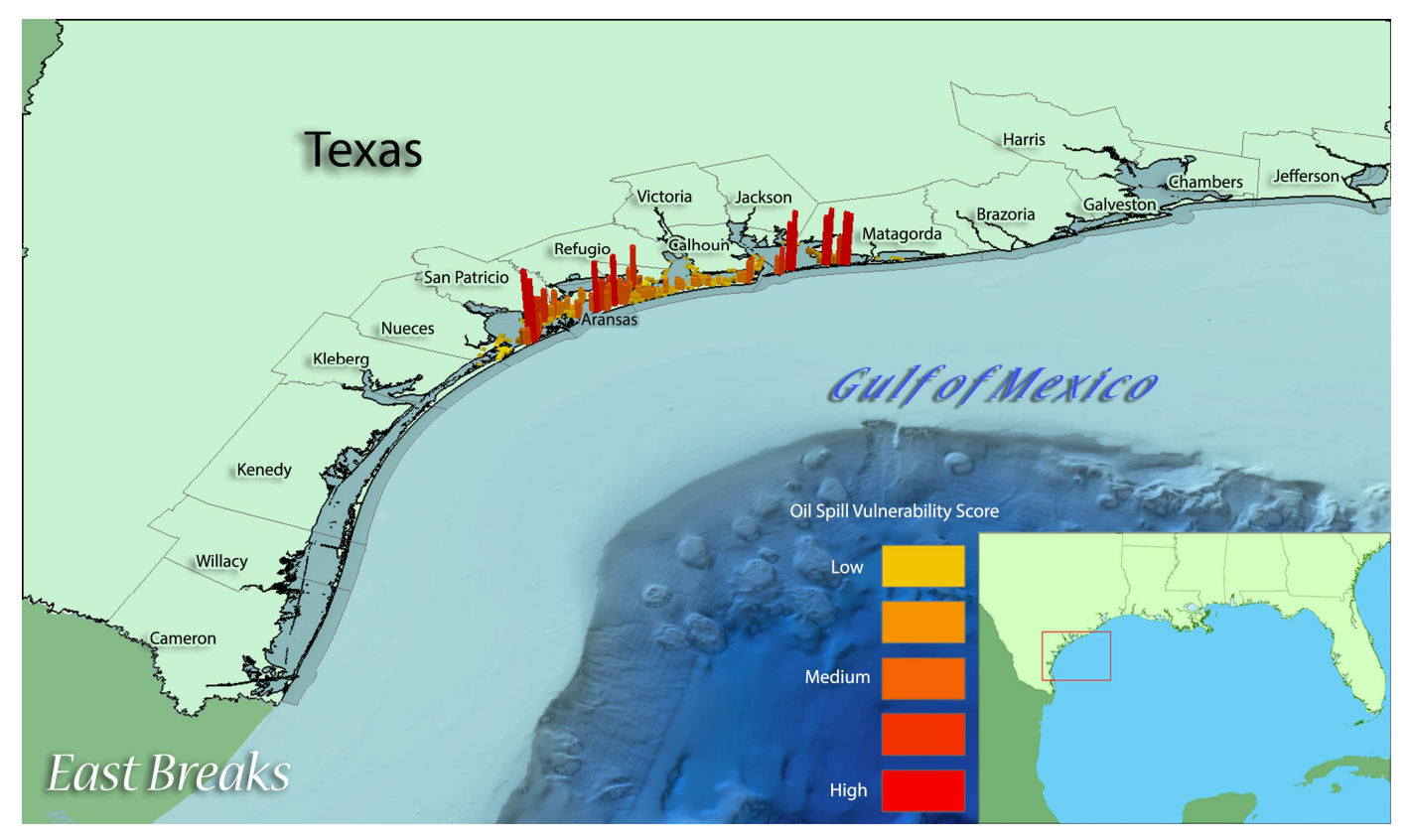

